\title{
Hepatitis C Virus and Hepatocellular Carcinoma: A Narrative Review
}

\author{
Page Axley ${ }^{1}$, Zunirah Ahmed ${ }^{1}$, Sujan Ravi ${ }^{1}$ and Ashwani K. Singal*2 \\ ${ }^{1}$ Department of Medicine, University of Alabama at Birmingham, Birmingham, AL, USA; ${ }^{2}$ Division of Gastroenterology and \\ Hepatology, University of Alabama at Birmingham, AL, USA
}

\begin{abstract}
Hepatocellular carcinoma (HCC) is a leading cause of liverrelated death worldwide. Hepatitis $\mathrm{C}$ virus (HCV) infection is a major cause of advanced hepatic fibrosis and cirrhosis, with significantly increased risk for development of HCC. The morbidity and mortality of HCV-related HCC remains high, as rates of $\mathrm{HCV}$ cirrhosis continue to increase. The long-term goal of antiviral therapy for chronic HCV is to reduce complications from cirrhosis, including HCC. The advent of new direct-acting antivirals with high rates of virological clearance has revolutionized cure of $\mathrm{HCV}$ infection. While the development of HCC in $\mathrm{HCV}$ patients who achieve disease sustained virologic response is reduced, these patients remain at risk for HCC, particularly those patients with advanced fibrosis and cirrhosis. This review outlines the epidemiology of HCC in chronic HCV, various mechanisms, risk factors and pathophysiology that contribute to this disease process, screening recommendations, and the available data on the impact of new direct-acting antiviral treatment on the development on HCC.
\end{abstract}

Citation of this article: Axley P, Ahmed Z, Ravi S, Singal AK. Hepatitis $C$ virus and hepatocellular carcinoma: a narrative review. J Clin Transl Hepatol 2018;6(1):79-84. doi: 10.14218/ JCTH.2017.00067.

\section{Introduction}

Hepatitis C virus (HCV), a hepatotropic RNA virus, is one of the leading causes of chronic liver disease. Hepatocellular carcinoma (HCC) is a major complication associated with HCV virus infection, with significant mortality and morbidity rates (Fig. 1). $\mathrm{HCV}$-induced development of HCC is a gradual process and is affected by the duration of disease and viral genotype. ${ }^{1}$ The goal of HCV treatment is to eliminate the infection, decrease the rate of transmission to other individuals and reduce the risk of development of HCC. ${ }^{2}$ Direct-acting antiviral (DAA) agents have emerged as promising treatment options and are associated with high sustained virological response (SVR) rate. $^{3}$ Despite the advent of highly effective treatment, the morbidity and incidence of HCV-related HCC remains high.

Keywords: Hepatitis C; Hepatocellular carcinoma; Direct-acting antiviral; Viral hepatitis.

Abbreviations: AFP, alpha-fetoprotein; DAA, direct-acting antiviral; HBV, hepatitis $B$ virus; HCC, hepatocellular carcinoma; HCV, hepatitis $C$ virus; HIV, human immunodeficiency virus; IFN, interferon; SVR, sustained virologic response.

Received: 13 October 2017; Revised: 14 November 2017; Accepted: 20 November 2017

*Correspondence to: Ashwani K. Singal, Division of Gastroenterology and Hepatology, University of Alabama Birmingham, AL 35294-0012, USA. Tel: +1-205975-9698, Fax: +1-205-975-0961, E-mail: ashwanisingal.com@gmail.com

\section{Epidemiology of HCV-related HCC}

HCC is the fifth most common cancer and second leading cause of cancer-related death worldwide. ${ }^{4}$ Chronic HCV infection is the leading cause of HCC in the western countries, and accounts for about $34 \%$ of HCC cases in the USA. ${ }^{5}$ Risk of HCC in HCV-infected patients is increased by 15 - to 20 -fold, with annual incidence of $\mathrm{HCC}$ being estimated at $1 \%$ to $4 \%$ in cirrhotics over a 30-year period. ${ }^{6}$ In 2012, a total of 170000 new cancer cases, or approximately $7.8 \%$ of all new cancers, were attributable to $\mathrm{HCV}^{7}$ Over the past decade, deaths from HCVattributable HCC increased by $21.1 \%$, during which time deaths from HCC secondary to causes other than HCV and alcohol remained stable. ${ }^{8}$

The incidence of HCV-related HCC varies with both geographic location and ethnicity. HCV is the leading etiology of HCC in the USA, Europe, Japan and South America, whereas hepatitis $B$ virus (HBV) is the major cause of $\mathrm{HCC}$ in the majority of Asia and Africa. ${ }^{9}$ An estimated $2.5 \%$ of the world population (177.5 million) are infected with HCV. ${ }^{10} \mathrm{HCV}$ infection became widespread in Japan in the 1920's and in the USA in the 1960 's. ${ }^{11} \mathrm{HCV}$ prevalence in Japan is around $3 \%$ and an estimated $85 \%$ of patients with HCC are infected with HCV. ${ }^{12}$ In contrast, the USA has a lower HCV prevalence of $1.8 \%$ of its population, with around $50-60 \%$ of patients with HCC being infected with $\mathrm{HCV}^{13}$ Japan's increased proportion of patients with HCC and HCV compared with the USA is influenced by the earlier onset of the HCV epidemic in Japan, suggesting that $\mathrm{HCV}$-associated $\mathrm{HCC}$ incidence will continue to rise in the USA. ${ }^{14}$

Within the USA population, HCC varies by ethnicity and age group, with Hispanic patients and patients born between the years of $1945-1965$ at highest risk of HCC. ${ }^{15}$ A large cohort study of 150000 USA veterans infected with HCV showed that Hispanic patients had the highest annual HCC incidence (at $7.8 \%$ ), likely related to the higher incidence of nonalcoholic fatty liver disease in this patient population. ${ }^{16}$ In a similar cohort, HCC incidence was shown to increase 2.5-fold, with tripling of mortality since to 2001, despite the introduction of DAAs. ${ }^{17}$ The impact of DAA therapy on HCC incidence will be discussed later in this review.

\section{Risk factors for development of HCC in chronic HCV infection}

Approximately $20 \%$ of chronic HCV-infected individuals develop liver cirrhosis within 20-30 years and once cirrhosis is established, the rate of HCC development is $1-4 \%$ annually. ${ }^{18}$ The predominant risk factors for the development of HCC in 


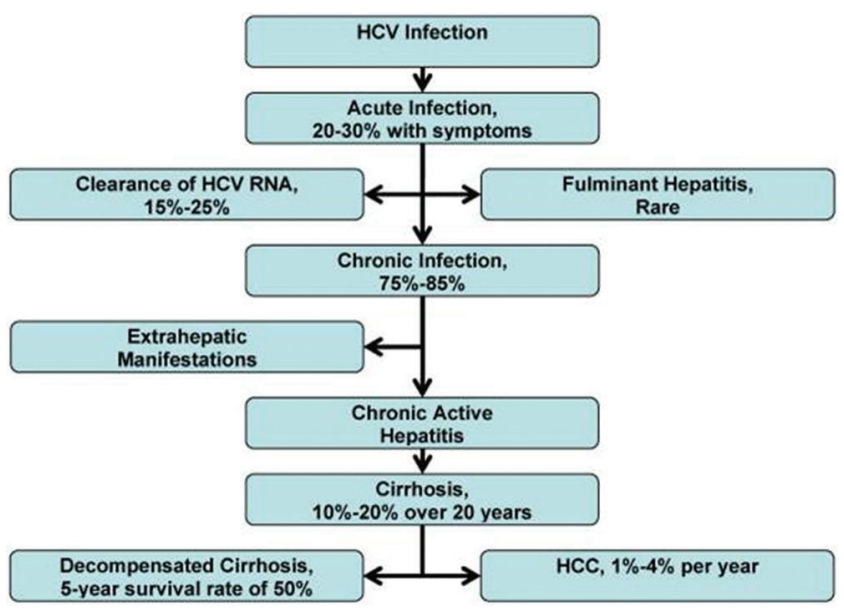

Fig. 1. Natural history of hepatitis C (HCV) infection. Reproduced from Chen et al. ${ }^{74}$ with permission.

chronic HCV infection include concurrent liver disease, viral genotype, lifestyle factors and the presence of obesity and diabetes mellitus. Coinfection with HBV and human immunodeficiency virus (HIV) significantly increases the risk of HCC in $\mathrm{HCV}$-infected patients. In HBV-HCV coinfection, HBV replication status is the crucial factor affecting the risk for HCC. Coinfected patients with undetectable HBV DNA have HCC risk equal to that of patients only infected with HCV. ${ }^{19}$ On the other hand, HCV patients with active HBV replication have twice the risk of $\mathrm{HCC}$ and a $21 \%$ increase in mortality compared to those with latent $\mathrm{HBV}$ and $\mathrm{HCV}^{19}$ Similarly, there is a substantial increase in HCC prevalence in HIV-HCV coinfected patients compared with HCV patients, with HCC occurring at a younger age in this population. ${ }^{20}$ This increase is attributed to amplified HCV replication, decreased immune response in HIV, and a more rapid progression to cirrhosis. ${ }^{21}$ In HIV-HCV coinfection, older age, cirrhosis, and low current CD4 cell count are associated with a higher incidence of HCC. ${ }^{22}$

Certain HCV viral genotypes are associated with higher risk of HCC. Compared to genotype 1, genotype 3 was associated with an $80 \%$ higher risk of HCC in a large cohort of patients from the USA Veterans Affairs medical system. ${ }^{23}$ While less common in developed countries, HCV genotype 6 has also been shown to confer increased risk for development of $\mathrm{HCC}^{24}$

$\mathrm{HCC}$ risk is also linked to lifestyle factors, such as smoking, alcohol use and coffee ingestion. Alcohol and smoking are associated with accelerated progression to HCC in HCV, likely via increased oxidative stress. ${ }^{25} \mathrm{~A}$ recent meta-analysis has shown a significant increase in relative risk of HCC in smokers with $\mathrm{HCV}$ compared with nonsmokers with $\mathrm{HCV}$, with relative risks of 23 and 7.9 respectively. ${ }^{25}$ There is a synergistic effect between alcohol and HCV on HCC, with a 2-fold increase in individuals who drink more than $60 \mathrm{~g}$ of alcohol daily. ${ }^{26}$ Furthermore, studies suggest that even past heavy alcoholism in people who have since stopped drinking can contribute to liver disease progression, cirrhosis and liver cancer in HCVinfected patients, including those who attain an SVR. ${ }^{27,28}$ While drinking alcohol has shown to increase HCV-related HCC, coffee consumption may be protective. Several studies support a significant decrease in HCC mortality with consumption of greater than or equal to 1 cup of coffee daily. ${ }^{28,29}$ In fact, coffee has been associated with both a decrease in the rate of progression to hepatic fibrosis and a decreased risk of HCC. ${ }^{30}$

Diabetes and obesity in individuals with HCV contribute to an increased risk of HCC. HCV infection has high comorbidity with diabetes mellitus, which confers a 2- to 3-fold increase in HCC risk. ${ }^{31,32}$ Pathogenesis of diabetes mellitus-mediated HCC development likely involves elevated insulin levels and insulin resistance leading to increased inflammation, cellular proliferation, apoptosis inhibition and generation of tumorcausing mutations. ${ }^{33}$ Available data also suggests that there is a 1.5- to 4-fold increased risk of HCC in patients with obesity. ${ }^{34}$ Increased proinflammatory cytokines, adiponectin and insulin resistance are potential mediators of carcinogenesis in HCV-related HCC. ${ }^{35}$

\section{Progression of HCV to HCC}

HCC development due to $\mathrm{HCV}$ is a stepwise process spanning over 20 to 40 years (Fig. 2). ${ }^{36} \mathrm{HCV}$ carcinogenesis is mediated by viral-induced factors and host-induced immunologic response. While evidence of a direct oncogenic effect of HCV on liver cells is limited to animal models, studies have shown that the HCV core protein may drive lipogenesis and impair oxidative stress metabolism. ${ }^{37} \mathrm{HCV}$ viral proteins can act directly on cell signaling pathways to promote HCC by inhibiting tumor suppressor genes and cell cycle check points or by causing activation of signaling pathways that up-regulate growth and division. ${ }^{38}$ Specific tumor suppressor genes inhibited by HCV core protein include retinoblastoma protein and p53 tumor suppressor. The loss of p53 and retinoblastoma is synergistic, leading to a greater degree of carcinogenesis. ${ }^{39}$ $\mathrm{HCV}$ nonstructural protein genes also promote fibrosis and the development of HCC through inducing transforming growth factor-beta and activating hepatic stellate cells. ${ }^{40}$

Host-induced immunologic response is mediated by tumor necrosis factor, interferons (IFNs) and chronic inflammation secondary to HCV. ${ }^{41}$ Repeated cell cycles are associated with accumulation of mutations that may transform hepatocytes to malignant cells. Genes most commonly mutated in HCC are telomerase reverse transcriptase, tumor protein 53 and $\beta$-catenin. ${ }^{42}$ These mutations threaten telomere maintenance and lead to increased oxidative stress. Most cases of HCC arise from hepatocytes in cirrhotic nodules that have accumulated enough mutations to reenter the cell cycle, reactivate telomerase, and progress through cancer checkpoints. ${ }^{43}$ Additionally, oxidative stress on the hepatocytes induced by the virus and host immune response leads to cell death and regeneration, also leading to mutations in the hepatocytes and ultimately, the development of HCC.

\section{Impact of newer DAA therapies on HCC}

Viral eradication with the traditional IFN-based treatment strategy has been associated with reduced risk of $\mathrm{HCC}$ development in patients with chronic HCV infection. ${ }^{44,45}$ The advent of DAA therapy has revolutionized the treatment of $\mathrm{HCV}$, with very high cure rates and excellent safety profile. ${ }^{46}$

Since the availability of DAAs, several observational studies have reported variable rates of occurrence of HCC. ${ }^{47}$ As experienced with IFN-based therapies, rates of occurrence of HCC were lower in two studies among patients achieving SVR after DAA therapy. ${ }^{48,49}$ However, in one study on patients with decompensated HCV-related cirrhosis who failed or were intolerant to IFN-based therapy, $5.4 \%$ of patients developed 
Axley P. et al: HCV and HCC

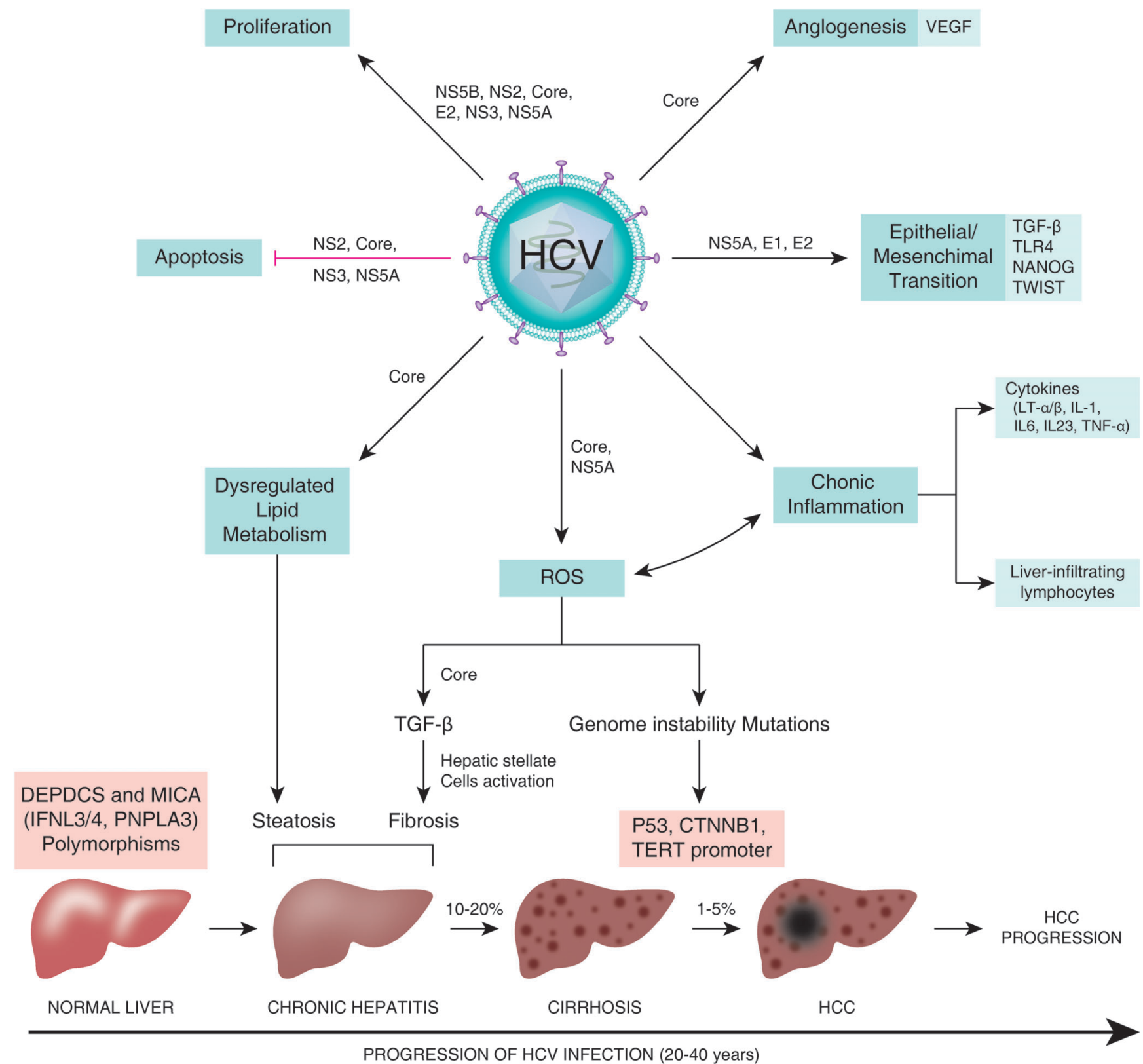

Fig. 2. HCV mechanisms for carcinogensis. HCV induces mitogenic, angiogenic and metastatic pathways, blocks cell death, triggers persistent inflammation and ROS production, and dysregulates host lipid metabolism. Copied with permission under CC 4.0 from Vescovo et al. ${ }^{36}$

new onset of HCC. ${ }^{50}$ Although the incidence was higher among patients treated with a DAA regimen alone as compared to those with an IFN-based therapy, this was not statistically significant after adjusting for confounders. ${ }^{51}$ Studies comparing the occurrence of HCC in patients taking a DAA with or without IFN also showed no significant differences. ${ }^{52}$ Similar observations were made in another study reported from a single USA center. ${ }^{53}$ Data on recurrence of HCC after treatment with DAAs is also conflicting, with higher rates of up to $35 \%$ in some studies ${ }^{54}$ and no difference compared to untreated patients in other studies. ${ }^{55}$ Among those that received DAAs, time to recurrence was also longer. ${ }^{56}$ Studies comparing HCC recurrence in patients who received
DAA versus IFN-based regimens did not show difference in the rates of recurrence. ${ }^{57}$

Studies on treatment of HCV infection in patients with HCC are even further limited. Although cure rates with DAA treatment have approached over $95 \%$ in most studies as well as in routine world practice experience, ${ }^{46}$ the rates remain low, at $52-62 \%$ among patients with active HCC. ${ }^{58}$ In one study, patients with active HCC were 8.5 times more likely to fail treatment. ${ }^{59}$ In another study, rate of radiological progression and exclusion from the liver transplant wait list was higher, although not by a statistically significant margin. ${ }^{60}$

Mechanisms of increased HCC rate after DAA treatment are not well understood. One speculated mechanism is altered 
Axley P. et al: HCV and HCC

immunological balance secondary to a rapid decrease in HCV viral load contributing to the tumor development occurrence and recurrence. ${ }^{61}$

\section{Screening for HCC in HCV patients}

High mortality associated with HCC makes it imperative for clinicians to commence screening for HCC early in the disease course. HCV-infected individuals with cirrhosis need systematic monitoring with liver ultrasound, possibly with adjunct serum alpha-fetoprotein (AFP) level. ${ }^{62-64}$ Ultrasound is the recommended imaging modality for screening, as it has higher sensitivity and specificity than AFP and is able to detect lesions $0.5-1 \mathrm{~cm}$ in diameter. ${ }^{65}$ The sensitivity of ultrasound is user-dependent, and the accuracy for detecting small nodules less than $0.5 \mathrm{~cm}$ is limited. Recently, computed tomography scan and magnetic resonance imaging have emerged as promising screening tools. ${ }^{66}$ Liver ultrasonography is mandatory prior to starting HCV treatment, within 12 weeks after its completion, and at 24-week intervals after that. ${ }^{62}$ Currently, AFP is only recommended to be used as an adjunctive screening tool when ultrasound is either not available or is of poor quality. ${ }^{67}$ However, in some cases the use of AFP alongside ultrasound imaging increased the sensitivity of $\mathrm{HCC}$ detection from $63 \%$ to $69 \%$. ${ }^{68}$

Whereas most cases of HCV-associated HCC occur in the background of cirrhosis, occasionally it may occur in the setting of bridging fibrosis. ${ }^{69}$ As a result, the current recommendations for HCC surveillance (liver ultrasound with or without AFP twice per year) are recommended for patients with cirrhosis and F3 fibrosis. ${ }^{70}$ As alluded to in the previous section, the data remain controversial on the risk of developing $\mathrm{HCC}$ after treatment with DAA.

Lifelong surveillance for HCC in patients with fibrosis and cirrhosis is associated with considerable economic and psychological implications. With emerging advancements in treatment modalities, there is evidence that fibrosis regression can occur after achieving SVR. ${ }^{71}$ There is lack of evidence on correlation between regression in cirrhosis determined histologically and risk of HCC. ${ }^{72}$ Based on limited data, post-SVR liver biopsies are neither routinely performed nor are they clinically practical. At this point, it is difficult to determine if serial biopsies would provide sufficient data to discontinue HCC surveillance based on histological regression of fibrosis. Similarly, studies on noninvasive biomarkers for fibrosis are also inconclusive in determining the regression in fibrosis post-SVR. ${ }^{73}$ Based on current available data, physicians should perform twice yearly hepatic imaging indefinitely post-SVR in patients with advanced fibrosis and cirrhosis.

\section{Conclusions}

$\mathrm{HCV}$-related $\mathrm{HCC}$ is increasing worldwide and is associated with high mortality. The risk of HCC is substantially reduced in patients who achieve viral eradication but is not completely eliminated, and patients with advanced fibrosis and cirrhosis require ongoing surveillance for HCC. Future research should be directed towards clarifying the role of DAA treatment on the development of HCC.

\section{Acknowledgements}

The work was supported by a faculty development grant to AKS by the American College of Gastroenterology.

\section{Conflict of interest}

The authors have no conflict of interests related to this publication.

\section{Author contributions}

Review of literature and drafting of manuscript (PA, ZA, SR), critical revision of the manuscript (AKS).

\section{References}

[1] Bruno S, Crosignani A, Maisonneuve P, Rossi S, Silini E, Mondelli MU. Hepatitis $C$ virus genotype $1 \mathrm{~b}$ as a major risk factor associated with hepatocellular carcinoma in patients with cirrhosis: a seventeen-year prospective cohort study. Hepatology 2007;46:1350-1356. doi: 10.1002/hep.21826.

[2] European Association for the Study of the Liver. EASL recommendations on treatment of hepatitis C 2016. J Hepatol 2017;66:153-194. doi: 10.1016/j. jhep.2016.09.001.

[3] Kohli A, Shaffer A, Sherman A, Kottilil S. Treatment of hepatitis C: a systematic review. JAMA 2014;312:631-640. doi: 10.1001/jama.2014.7085.

[4] Bosetti C, Turati F, La Vecchia C. Hepatocellular carcinoma epidemiology. Best Pract Res Clin Gastroenterol 2014;28:753-770. doi: 10.1016/j.bpg.2014. 08.007.

[5] de Martel C, Maucort-Boulch D, Plummer M, Franceschi S. World-wide relative contribution of hepatitis $B$ and $C$ viruses in hepatocellular carcinoma. Hepatology 2015;62:1190-1200. doi: 10.1002/hep.27969.

[6] El-Serag HB. Epidemiology of viral hepatitis and hepatocellular carcinoma. Gastroenterology 2012;142:1264-1273.e1. doi: 10.1053/j.gastro.2011.12. 061.

[7] Plummer M, de Martel C, Vignat J, Ferlay J, Bray F, Franceschi S. Global burden of cancers attributable to infections in 2012: a synthetic analysis. Lancet Glob Health 2016;4:e609-e616. doi: 10.1016/S2214-109X(16)30143-7.

[8] GBD 2015 Mortality and Causes of Death Collaborators. Global, regional, and national life expectancy, all-cause mortality, and cause-specific mortality for 249 causes of death, 1980-2015: a systematic analysis for the Global Burden of Disease Study 2015. Lancet 2016;388:1459-1544. doi: 10.1016/S01406736(16)31012-1.

[9] Yang JD, Roberts LR. Hepatocellular carcinoma: A global view. Nat Rev Gastroenterol Hepatol 2010;7:448-458. doi: 10.1038/nrgastro.2010.100.

[10] Petruzziello A, Marigliano S, Loquercio G, Cozzolino A, Cacciapuoti C. Global epidemiology of hepatitis $C$ virus infection: An up-date of the distribution and circulation of hepatitis C virus genotypes. World J Gastroenterol 2016;22: 7824-7840. doi: 10.3748/wjg.v22.i34.7824.

[11] Tanaka Y, Kurbanov F, Mano S, Orito E, Vargas V, Esteban JI, et al. Molecular tracing of the global hepatitis $C$ virus epidemic predicts regional patterns of hepatocellular carcinoma mortality. Gastroenterology 2006;130:703-714. doi: 10.1053/j.gastro.2006.01.032.

[12] Sievert W, Altraif I, Razavi HA, Abdo A, Ahmed EA, Alomair A, et al. A systematic review of hepatitis $C$ virus epidemiology in Asia, Australia and Egypt. Liver Int 2011;31:61-80. doi: 10.1111/j.1478-3231.2011.02540.x.

[13] Altekruse SF, Henley SJ, Cucinelli JE, McGlynn KA. Changing hepatocellular carcinoma incidence and liver cancer mortality rates in the United States. Am J Gastroenterol 2014;109:542-553. doi: 10.1038/ajg.2014.11.

[14] Perz JF, Armstrong GL, Farrington LA, Hutin YJ, Bell BP. The contributions of hepatitis $B$ virus and hepatitis $C$ virus infections to cirrhosis and primary liver cancer worldwide. J Hepatol 2006;45:529-538. doi: 10.1016/j.jhep.2006. 05.013.

[15] Yan M, Ha J, Aguilar M, Bhuket T, Liu B, Gish RG, et al. Birth cohort-specific disparities in hepatocellular carcinoma stage at diagnosis, treatment, and long-term survival. J Hepatol 2016;64:326-332. doi: 10.1016/j.jhep. 2015.09.006.

[16] El-Serag HB, Kramer J, Duan Z, Kanwal F. Racial differences in the progression to cirrhosis and hepatocellular carcinoma in HCV-infected veterans. Am J Gastroenterol 2014;109:1427-1435. doi: 10.1038/ajg.2014.214.

[17] Beste LA, Leipertz SL, Green PK, Dominitz JA, Ross D, Ioannou GN. Trends in burden of cirrhosis and hepatocellular carcinoma by underlying liver disease in US veterans, 2001-2013. Gastroenterology 2015;149:1471-1482.e5. doi: 10.1053/j.gastro.2015.07.056. 
[18] Omland LH, Krarup H, Jepsen $\mathrm{P}$, Georgsen J, Harritshøj LH, Riisom K, et al. Mortality in patients with chronic and cleared hepatitis $C$ viral infection: a nationwide cohort study. J Hepatol 2010;53:36-42. doi: 10.1016/j.jhep. 2010.01.033.

[19] Kruse RL, Kramer JR, Tyson GL, Duan Z, Chen L, El-Serag HB, et al. Clinical outcomes of hepatitis B virus coinfection in a United States cohort of hepatitis C virus-infected patients. Hepatology 2014;60:1871-1878. doi: 10. 1002/hep. 27337.

[20] Kramer JR, Kowalkowski MA, Duan Z, Chiao EY. The effect of HIV viral control on the incidence of hepatocellular carcinoma in veterans with hepatitis $C$ and HIV coinfection. J Acquir Immune Defic Syndr 2015;68:456-462. doi: 10. 1097/QAI.0000000000000494.

[21] Ioannou GN, Bryson CL, Weiss NS, Miller R, Scott JD, Boyko EJ. The prevalence of cirrhosis and hepatocellular carcinoma in patients with human immunodeficiency virus infection. Hepatology 2013;57:249-257. doi: 10. 1002/hep. 25800 .

[22] Gjærde LI, Shepherd L, Jablonowska E, Lazzarin A, Rougemont M, Darling K, et $a$. Trends in incidences and risk factors for hepatocellular carcinoma and other liver events in HIV and hepatitis $C$ virus-coinfected individuals from 2001 to 2014: a multicohort study. Clin Infect Dis 2016;63:821-829. doi: $10.1093 / \mathrm{cid} / \mathrm{ciw} 380$.

[23] Kanwal F, Kramer JR, Ilyas J, Duan Z, El-Serag HB. HCV genotype 3 is associated with an increased risk of cirrhosis and hepatocellular cancer in a national sample of U.S. Veterans with HCV. Hepatology 2014;60:98-105. doi: 10.1002/hep.27095.

[24] Lee MH, Hsiao TI, Subramaniam SR, Le AK, Vu VD, Trinh HN, et al. HCV genotype 6 increased the risk for hepatocellular carcinoma among asian patients with liver cirrhosis. Am J Gastroenterol 2017;112:1111-1119. doi: 10.1038/ajg.2017.123.

[25] Chuang SC, Lee YC, Hashibe M, Dai M, Zheng T, Boffetta P. Interaction between cigarette smoking and hepatitis $B$ and $C$ virus infection on the risk of liver cancer: a meta-analysis. Cancer Epidemiol Biomarkers Prev 2010; 19:1261-1268. doi: 10.1158/1055-9965.EPI-09-1297.

[26] Donato F, Tagger A, Gelatti U, Parrinello G, Boffetta P, Albertini A, et al. Alcohol and hepatocellular carcinoma: the effect of lifetime intake and hepatitis virus infections in men and women. Am J Epidemiol 2002;155:323331. doi: 10.1093/aje/155.4.323.

[27] Hagström H. Alcohol consumption in concomitant liver disease: how much is too much? Curr Hepatol Rep 2017;16:152-157. doi: 10.1007/s11901-0170343-0.

[28] Singal AK, Anand BS. Mechanisms of synergy between alcohol and hepatitis C virus. J Clin Gastroenterol 2007;41:761-772. doi: 10.1097/MCG. ob013e3180381584.

[29] Wakai K, Kurozawa Y, Shibata A, Fujita Y, Kotani K, Ogimoto I, et al. Liver cancer risk, coffee, and hepatitis $C$ virus infection: a nested case-control study in Japan. Br J Cancer 2007;97:426-428. doi: 10.1038/sj.bjc.6603891.

[30] Saab S, Mallam D, Cox GA 2nd, Tong MJ. Impact of coffee on liver diseases: a systematic review. Liver Int 2014;34:495-504. doi: 10.1111/liv.12304.

[31] Huang TS, Lin CL, Lu MJ, Yeh CT, Liang KH, Sun CC, et al. Diabetes, hepatocellular carcinoma, and mortality in hepatitis $\mathrm{C}$-infected patients: A populationbased cohort study. J Gastroenterol Hepatol 2017;32:1355-1362. doi: 10. $1111 /$ jgh.13670.

[32] Raff EJ, Kakati D, Bloomer JR, Shoreibah M, Rasheed K, Singal AK. Diabetes mellitus predicts occurrence of cirrhosis and hepatocellular cancer in alcoholic liver and non-alcoholic fatty liver diseases. J Clin Transl Hepatol 2015; 3:9-16. doi: 10.14218/JCTH.2015.00001.

[33] Li X, Xu H, Gao Y, Pan M, Wang L, Gao P. Diabetes mellitus increases the risk of hepatocellular carcinoma in treatment-naïve chronic hepatitis $C$ patients in China. Medicine (Baltimore) 2017;96:e6508. doi: 10.1097/MD. 0000000000006508.

[34] Calle EE, Rodriguez C, Walker-Thurmond K, Thun MJ. Overweight, obesity, and mortality from cancer in a prospectively studied cohort of U.S. adults. N Engl J Med 2003;348:1625-1638. doi: 10.1056/NEJMoa021423.

[35] Rao H, Wu E, Fu S, Yang M, Feng B, Lin A, et al. The higher prevalence of truncal obesity and diabetes in American than Chinese patients with chronic hepatitis $\mathrm{C}$ might contribute to more rapid progression to advanced liver disease. Aliment Pharmacol Ther 2017;46:731-740. doi: 10.1111/apt.14273.

[36] Vescovo T, Refolo G, Vitagliano G, Fimia GM, Piacentini M. Molecular mechanisms of hepatitis $C$ virus-induced hepatocellular carcinoma. Clin Microbiol Infect 2016;22:853-861. doi: 10.1016/j.cmi.2016.07.019.

[37] Li Y, Boehning DF, Qian T, Popov VL, Weinman SA. Hepatitis C virus core protein increases mitochondrial ROS production by stimulation of $\mathrm{Ca} 2+$ uniporter activity. FASEB J 2007;21:2474-2485. doi: 10.1096/fj.06-7345com.

[38] Okuda M, Li K, Beard MR, Showalter LA, Scholle F, Lemon SM, et al. Mitochondrial injury, oxidative stress, and antioxidant gene expression are induced by hepatitis C virus core protein. Gastroenterology 2002;122: 366-375. doi: 10.1053/gast.2002.30983.

[39] Lemon SM, McGivern DR. Is hepatitis C virus carcinogenic? Gastroenterology 2012;142:1274-1278. doi: 10.1053/j.gastro.2012.01.045.
[40] Schulze-Krebs A, Preimel D, Popov Y, Bartenschlager R, Lohmann V, Pinzani $M$, et al. Hepatitis $C$ virus-replicating hepatocytes induce fibrogenic activation of hepatic stellate cells. Gastroenterology 2005;129:246-258. doi: 10 . 1053/j.gastro.2005.03.089.

[41] Yu GY, He G, Li CY, Tang M, Grivennikov S, Tsai WT, et al. Hepatic expression of HCV RNA-dependent RNA polymerase triggers innate immune signaling and cytokine production. Mol Cell 2012;48:313-321. doi: 10.1016/j.molcel. 2012.07.032.

[42] Tomasetti C, Li L, Vogelstein B. Stem cell divisions, somatic mutations, cancer etiology, and cancer prevention. Science 2017;355:1330-1334. doi: 10.1126/science.aaf9011.

[43] Nault JC, Calderaro J, Di Tommaso L, Balabaud C, Zafrani ES, Bioulac-Sage P, et al. Telomerase reverse transcriptase promoter mutation is an early somatic genetic alteration in the transformation of premalignant nodules in hepatocellular carcinoma on cirrhosis. Hepatology 2014;60:1983-1992. doi: 10.1002/hep.27372.

[44] Morgan RL, Baack B, Smith BD, Yartel A, Pitasi M, Falck-Ytter Y. Eradication of hepatitis $C$ virus infection and the development of hepatocellular carcinoma: a meta-analysis of observational studies. Ann Intern Med 2013;158:329337. doi: 10.7326/0003-4819-158-5-201303050-00005.

[45] Singal AK, Singh A, Jaganmohan S, Guturu P, Mummadi R, Kuo YF, et al. Antiviral therapy reduces risk of hepatocellular carcinoma in patients with hepatitis C virus-related cirrhosis. Clin Gastroenterol Hepatol 2010;8:192199. doi: 10.1016/j.cgh.2009.10.026.

[46] Majumdar A, Kitson MT, Roberts SK. Systematic review: current concepts and challenges for the direct-acting antiviral era in hepatitis $\mathrm{C}$ cirrhosis. Aliment Pharmacol Ther 2016;43:1276-1292. doi: 10.1111/apt.13633.

[47] Backus LI, Belperio PS, Shahoumian TA, Mole LA. Impact of sustained virologic response with direct-acting antiviral treatment on mortality in patients with advanced liver disease. Hepatology 2017. doi: 10.1002/hep.29408.

[48] Kanwal F, Kramer ], Asch SM, Chayanupatkul M, Cao Y, El-Serag HB. Risk of hepatocellular cancer in $\mathrm{HCV}$ patients treated with direct-acting antiviral agents. Gastroenterology 2017;153:996-1005.e1. doi: 10.1053/j.gastro. 2017.06.012.

[49] Zeng QL, Li ZQ, Liang HX, Xu GH, Li CX, Zhang DW, et al. Unexpected high incidence of hepatocellular carcinoma in patients with hepatitis $C$ in the era of DAAs: Too alarming? J Hepatol 2016;65:1068-1069. doi: 10.1016/j.jhep. 2016.07.029.

[50] Foster GR, Irving WL, Cheung MC, Walker AJ, Hudson BE, Verma $S$, et al. Impact of direct acting antiviral therapy in patients with chronic hepatitis $C$ and decompensated cirrhosis. J Hepatol 2016;64:1224-1231. doi: 10. 1016/j.jhep.2016.01.029.

[51] Ioannou GN, Green PK, Berry K. HCV eradication induced by direct-acting antiviral agents reduces the risk of hepatocellular carcinoma. J Hepatol 2017. doi: 10.1016/j.jhep.2017.08.030.

[52] Bielen R, Moreno C, Van Vlierberghe $H$, Bourgeois S, Mulkay JP, Vanwolleghem $\mathrm{T}$, et al. The risk of early occurrence and recurrence of hepatocellular carcinoma in hepatitis C-infected patients treated with direct-acting antivirals with and without pegylated interferon: A Belgian experience. J Viral Hepat 2017;24:976-981. doi: 10.1111/jvh.12726.

[53] Ravi S, Axley P, Jones D, Kodali S, Simpson H, McGuire BM, et al. Unusually high rates of hepatocellular carcinoma after treatment with direct-acting antiviral therapy for hepatitis C related cirrhosis. Gastroenterology 2017; 152:911-912. doi: 10.1053/j.gastro.2016.12.021.

[54] Ikeda K, Kawamura Y, Kobayashi M, Kominami Y, Fujiyama S, Sezaki H, et al. Direct-acting antivirals decreased tumor recurrence after initial treatment of hepatitis C virus-related hepatocellular carcinoma. Dig Dis Sci 2017;62: 2932-2942. doi: 10.1007/s10620-017-4739-z.

[55] Minami T, Tateishi R, Nakagomi R, Fujiwara N, Sato M, Enooku K, et al. The impact of direct-acting antivirals on early tumor recurrence after radiofrequency ablation in hepatitis C-related hepatocellular carcinoma. J Hepatol 2016;65:1272-1273. doi: 10.1016/j.jhep.2016.07.043.

[56] Petta S, Cabibbo G, Barbara M, Attardo S, Bucci L, Farinati F, et al. Hepatocellular carcinoma recurrence in patients with curative resection or ablation: impact of HCV eradication does not depend on the use of interferon. Aliment Pharmacol Ther 2017;45:160-168. doi: 10.1111/apt.13821.

[57] Waziry R, Hajarizadeh B, Grebely J, Amin J, Law M, Danta M, et al. Hepatocellular carcinoma risk following direct-acting antiviral HCV therapy: A systematic review, meta-analyses, and meta-regression. J Hepatol 2017;67: 1204-1212. doi: 10.1016/j.jhep.2017.07.025.

[58] Yang JD, Aqel BA, Pungpapong S, Gores G], Roberts LR, Leise MD. Direct acting antiviral therapy and tumor recurrence after liver transplantation for hepatitis C-associated hepatocellular carcinoma. J Hepatol 2016;65:859860. doi: 10.1016/j.jhep.2016.06.023.

[59] Prenner SB, VanWagner LB, Flamm SL, Salem R, Lewandowski RJ, Kulik L. Hepatocellular carcinoma decreases the chance of successful hepatitis C virus therapy with direct-acting antivirals. J Hepatol 2017;66:1173-1181. doi: 10.1016/j.jhep.2017.01.020.

[60] Zanetto A, Shalaby S, Vitale A, Mescoli C, Ferrarese A, Gambato M, et al. Dropout rate from the liver transplant waiting list because of hepatocellular 
carcinoma progression in hepatitis $C$ virus-infected patients treated with direct-acting antivirals. Liver Transpl 2017;23:1103-1112. doi: 10.1002/lt. 24790.

[61] Grandhe S, Frenette CT. Occurrence and recurrence of hepatocellular carcinoma after successful direct-acting antiviral therapy for patients with chronic hepatitis C virus infection. Gastroenterol Hepatol (N Y) 2017;13: 421-425.

[62] Polish Group of Experts for HCV, Halota W, Flisiak R, Juszczyk J, Małkowski $\mathrm{P}_{\text {, }}$ Pawłowska $M$, et al. Recommendations for the treatment of hepatitis $C$ in 2017. Clin Exp Hepatol 2017;3:47-55. doi: 10.5114/ceh.2017.67782.

[63] Fitzmorris P, Shoreibah M, Anand BS, Singal AK. Management of hepatocellular carcinoma. J Cancer Res Clin Oncol 2015;141:861-876. doi: 10.1007/ s00432-014-1806-0.

[64] Fitzmorris P, Singal AK. Surveillance and diagnosis of hepatocellular carcinoma. Gastroenterol Hepatol (N Y) 2015;11:38-46.

[65] Bruix J, Sherman M. Management of hepatocellular carcinoma: an update. Hepatology 2011;53:1020-1022. doi: 10.1002/hep.24199.

[66] Parikh A, Taouli B. Imaging of hepatocellular carcinoma: current concepts. Recent Results Cancer Res 2013;190:33-55. doi: 10.1007/978-3-64216037-0_3.

[67] Daniele B, Bencivenga A, Megna AS, Tinessa V. Alpha-fetoprotein and ultrasonography screening for hepatocellular carcinoma. Gastroenterology 2004; 127:S108-S112. doi: 10.1053/j.gastro.2004.09.023.
[68] Singal A, Volk ML, Waljee A, Salgia R, Higgins $P$, Rogers MA, et al. Metaanalysis: surveillance with ultrasound for early-stage hepatocellular carcinoma in patients with cirrhosis. Aliment Pharmacol Ther 2009;30:37-47. doi: 10.1111/j.1365-2036.2009.04014.x.

[69] Lok AS, Seeff LB, Morgan TR, di Bisceglie AM, Sterling RK, Curto TM, et al. Incidence of hepatocellular carcinoma and associated risk factors in hepatitis C-related advanced liver disease. Gastroenterology 2009;136:138-148. doi: $10.1053 /$ j.gastro.2008.09.014.

[70] EASL recommendations on treatment of hepatitis C 2015. J Hepatol 2015; 63:199-236. doi: 10.1016/j.jhep.2015.03.025.

[71] Lee YA, Friedman SL. Reversal, maintenance or progression: what happens to the liver after a virologic cure of hepatitis C? Antiviral Res 2014;107:2330. doi: 10.1016/j.antiviral.2014.03.012.

[72] Tachi Y, Hirai T, Miyata A, Ohara K, Iida T, Ishizu Y, et al. Progressive fibrosis significantly correlates with hepatocellular carcinoma in patients with a sustained virological response. Hepatol Res 2015;45:238-246. doi: 10.1111/ hepr.12331.

[73] Tachi Y, Hirai T, Toyoda H, Tada T, Hayashi K, Honda T, et al. Predictive ability of laboratory indices for liver fibrosis in patients with chronic hepatitis $\mathrm{C}$ after the eradication of hepatitis C virus. PLoS One 2015;10:e0133515. doi: 10. 1371/journal.pone. 0133515 .

[74] Chen SL, Morgan TR. The natural history of hepatitis C virus (HCV) infection. Int J Med Sci 2006;3:47-52. doi: 10.7150/ijms.3.47. 